\title{
Perioperatieve behandelingen en radicale cystectomie voor blaaskanker. Een trendanalyse over 10.338 patiënten in Nederland
}

\author{
Tom J. N. Hermans ${ }^{1}$ Elisabeth E. Fransen van de Putte ${ }^{1}$ Simon Horenblas ${ }^{1} \cdot$ Valery Lemmens $^{2,3}$ • \\ Katja Aben $^{2,4} \cdot$ Michiel S. van der Heijden ${ }^{5}$ Laurens V. Beerepoot ${ }^{6} \cdot$ Rob H. Verhoeven $^{2} \cdot$ Bas W. G. van \\ Rhijn ${ }^{1}$
}

Published online: 4 August 2016

(C) The Author(s) 2016. This article is available at SpringerLink with Open Access.

\section{Samenvatting}

Achtergrond In Europa zijn epidemiologische data betreffende perioperatieve behandelingen $(\mathrm{PB})$ en radicale cystectomie (RC) niet voorhanden. Wij onderzochten trends in de toepassing van neoadjuvante chemotherapie (NAC), neoadjuvante radiotherapie (NAR), adjuvante chemotherapie (AC) en adjuvante radiotherapie (AR) en $\mathrm{RC}$ in een bepaalde periode in Nederland. Tevens onderzochten wij patiënt- en ziekenhuisfactoren die geassocieerd waren met PB.

Methoden In deze landelijke, retrospectieve studie werden alle patiënten uit de Nederlandse Kanker Registratie (NKR) geïncludeerd, die een $\mathrm{RC}$ met curatieve intentie ondergin-

De auteurs R.H. Verhoeven, L.V. Beerepoot en B.W.G. van Rhijn hebben in gelijke mate aan dit manuscript bijgedragen.

Dit artikel werd eerder gepubliceerd onder de titel Perioperative treatment and radical cystectomy for bladder cancer -

a population based trend analysis of 10,338 patients in the

Netherlands. Indien u wenst te refereren gaarne altijd citeren: Eur

J Cancer. 2016 Feb;54:18-26.

dr. Bas W. G. van Rhijn

basvanrhijn@hotmail.com

1 afdeling Chirurgische Oncologie, divisie Urologie, Antoni van Leeuwenhoek, Amsterdam, Nederland

2 afdeling Onderzoek, Integraal Kankercentrum Nederland, Utrecht, Nederland

3 afdeling Public Health, Erasmus Universitair Medisch Centrum, Rotterdam, Nederland

4 afdeling Health Evidence, Radboud Universitair Medisch Centrum, Nijmegen, Nederland

5 afdeling Medische Oncologie, Antoni van Leeuwenhoek, Amsterdam, Nederland

6 afdeling Medische Oncologie, Elisabeth-Twee Steden Ziekenhuis, Tilburg, Nederland gen voor cTa/is, T1-4, N0-3, M0-1 blaaskanker (BK) tussen 1995 en 2013. De toepassing van PB in de loop van de tijd werd vergeleken met de uitkomst van Chi-kwadraattesten. Multivariabele logistische regressieanalyses werden uitgevoerd om karakteristieken te identificeren die zijn geassocieerd met PB. De subgroepen cT2-4, N0 of Nx, M0 of Mx en cT2-4N0M0 werden afzonderlijk geanalyseerd. Resultaten In totaal werden 10.338 patiënten geïncludeerd. $86 \%$ onderging geen $\mathrm{PB}, 7,0 \%$ ontving NAC (of inductiechemotherapie (IC)), 3,2\% NAR, 1,8\% AC en 2,1\% AR. De toepassing van NAC steeg van $0,6 \%$ in 1995 naar $21 \%$ in $2013(p<0,001)$, de toepassing van NAR daalde van $15 \%$ naar $0,4 \%(p<0,001)$. AC en AR werden in 2013 in $<1,5 \%$ van de gevallen toegepast. Vergelijkbare trends werden gezien bij 6.032 cT2-4N0M0 BK-patiënten. Multivariabele logistische regressieanalyse toonde dat een lagere leeftijd, $\geq \mathrm{cT} 3, \geq \mathrm{cN} 1$ en behandeling in academische en opleidingsziekenhuizen geassocieerd waren met de toepassing van NAC (inclusief IC) (alle $p<0,05$ ).

Conclusie De stijging in de toepassing van NAC in de laatste twee decennia toont een langzame, maar gestage adaptatie van internationale richtlijnen in Nederland. Betreffende de toepassing van NAC bestaan er aanzienlijke variaties in patiënt- en ziekenhuiskarakteristieken. In tegenstelling tot NAC worden NAR, AR en AC nauwelijks (meer) toegepast.

Trefwoorden blaaskanker - neoadjuvant - radiotherapie . chemotherapie $\cdot$ adjuvant $\cdot$ cystectomie 


\section{Perioperative treatment and radical cystectomy for bladder cancer - a population based trend analysis of 10,338 patients in the Netherlands}

\begin{abstract}
Background In Europe, population-based data concerning perioperative treatment (PT) and radical cystectomy (RC) are lacking. We assessed temporal tends in PT (neoadjuvant chemotherapy (NAC), neoadjuvant radiotherapy (NAR), adjuvant chemotherapy (AC), adjuvant radiotherapy (AR)) and RC in the Netherlands and identified patients' and hospital characteristics associated with PT.

Methods This nationwide, retrospective, population-based study included cTa/is, T1-4, N0-3, M0-1 bladder cancer (BC) patients from the Netherlands Cancer Registry who underwent RC with curative intent between 1995 and 2013. PT-administration over time was compared with chi-square tests. Multivariable logistic regression analyses were performed to identify characteristics associated with PT usage. The sub-groups cT2-4N0M0 and cT2-4, N0 or Nx, M0 or Mx were separately analyzed.

Results In total, 10,338 patients met inclusion criteria. $86 \%$ did not receive PT, $7.0 \%$ received NAC (or induction chemotherapy (IC)), 3.2\% NAR, $1.8 \%$ AC, and $2.1 \%$ AR. NAC usage increased from $0.6 \%$ in 1995 to $21.2 \%$ in 2013 $(p<0.001)$, application of NAR decreased from $15.1 \%$ to $0.4 \%(p<0.001)$. Usage of AC and AR in 2013 was $<1.5 \%$. Comparable temporal trends were found in 6,032 patients staged cT2-4N0M0. Multivariable logistic regression analysis revealed that younger age, $\geq \mathrm{cT} 3, \geq \mathrm{cN} 1$ and treatment in academic/teaching hospitals were associated with NAC or IC (all $p<0.05$ ).

Conclusions The increase in NAC administration in the Netherlands reflects a slow but steady adoption of evidence based guidelines over the last two decades. Considerable variability in patients' and hospital characteristics in the likelihood of receiving NAC exists. Conversely, NAR, AR and $\mathrm{AC}$ are hardly administered anymore.
\end{abstract}

Keywords bladder - cancer · chemotherapy · radiotherapy $\cdot$ peri-operative

\section{Introductie}

De afgelopen 30 jaar zijn er bij de behandeling van het spierinvasieve blaascarcinoom (SIBC) geen significante verbeteringen in stadiumspecifieke overleving geboekt [1]. Dit weerspiegelt mogelijk de beperkingen van lokale therapie alleen, dat wil zeggen radicale cystectomie (RC) of uitwendige bestraling. Potentiële middelen om de overleving te verbeteren, betreffen de toepassing van perioperatieve radiotherapie en/of cisplatine bevattende combinatiechemotherapie (CBCC) [2-4].

Bij de behandeling van het SIBC verlagen neoadjuvante radiotherapie (NAR) en adjuvante radiotherapie (AR) het risico op een lokaal recidief door vermindering van tumormassa en sterilisatie van microscopische residuen. Er bestaan echter geen data van goede kwaliteit die ook levensverlenging onderschrijven [2-5]. Overlevingsdata betreffende neoadjuvante chemotherapie (NAC) zijn robuuster [4, 6]. Twee grote gerandomiseerde studies (RCT) onderzochten het effect van CBCC voorafgaand aan $\mathrm{RC}$ of radiotherapie versus lokale therapie, op cT2-T4a-, N0- of Nx-, M0- of Mx-blaaskanker (BK). Het risico op overlijden daalde door deze behandeling met 16-33\%, waardoor de tienjaarsoverleving verbeterde van $30 \%$ naar $36 \%$. Het ziektespecifieke risico op overlijden werd ook significant gereduceerd met 17-66\% [7, 8]. Een derde studie betreffende NAC concludeerde dat complete downstaging (CD) na NAC (ypT0N0) na vijf jaar geassocieerd was met een risicoverlaging van $31 \%$ op overlijden in vergelijking met CD controlepatiënten (pTON0) [9]. Bewijs voor de toepassing van adjuvante chemotherapie (AC) bij SIBC is tegenstrijdig. Een recente meta-analyse van studies van beperkte kwaliteit toonde een verbetering in ziektevrije overleving van $34 \%$. Vooral patiënten met CBCC en klierpositieve ziekte $(\mathrm{pN})$ profiteerden hiervan [3]. Een recente analyse van de National Cancer Data Base Registry in de Verenigde Staten toonde een stijging van de toepassing van NAC bij gelokaliseerde, alsmede lokaal uitgebreide kliernegatieve ziekte van $10 \%$ in 2006 naar $21 \%$ in 2010. De toepassing van AC bleef stabiel met $21 \%$ [10]. In Europa zijn vooralsnog geen epidemiologische data beschikbaar. Een vragenlijstonderzoek dat werd uitgevoerd in grote Europese centra in 2012, rapporteerde dat NAC werd overwogen bij 9-22\% van de patiënten bij wie RC werd overwogen [11]. Multimodale therapie, voornamelijk met CBCC, wordt beschouwd als 'state of the art' en wordt geadviseerd in actuele internationale richtlijnen. CBCC kan neoadjuvant bij ongeveer 50-60\% van de patiënten worden toegepast; $90 \%$ van de patiënten is in staat drie of meer cycli af te ronden [6, 12, 13]. Adjuvant wordt de toediening door complicaties ten gevolge van de $\mathrm{RC}$ in $30 \%$ van de gevallen beperkt [14]. Hoewel verruiming van de toepassing van CBCC theoretisch mogelijk is, zijn de acceptatie en implementatie van deze behandeling slechts langzaam verlopen. Wij onderzochten de toepassing van perioperatieve behandelingen (PB) middels de data van de NKR Nederlandse Kanker Registratie van 10.338 patiënten die een RC met curatieve intentie ondergingen tussen 1995 en 2013. Tevens identificeerden wij patiënt- en ziekenhuisfactoren die geassocieerd waren met het gebruik van PB [15]. 
Figuur 1 a Jaarlijkse aandeel perioperatieve behandelingen van 10.338 BK-patiënten (= gehele studiepopulatie) die zijn geregistreerd in de NKR, die tussen 1995 en 2013 een radicale cystectomie ondergingen. NB. Neoadjuvante chemotherapie bevat ook inductiechemotherapie voor cN1-3- en/of cM1-ziekte. b Jaarlijkse aandeel perioperatieve behandelingen van 7.295 cT2-4 N0- of Nx M0of Mx-BK-patiënten die zijn geregistreerd in de NKR, die tussen 1995 en 2013 RC ondergingen. c Het jaarlijkse aandeel perioperatieve behandelingen van 6.032 cT2-4 N0 M0-BK-patiënten die zijn geregistreerd in de NKR, die tussen 1995 en 2013 een RC ondergingen [15].
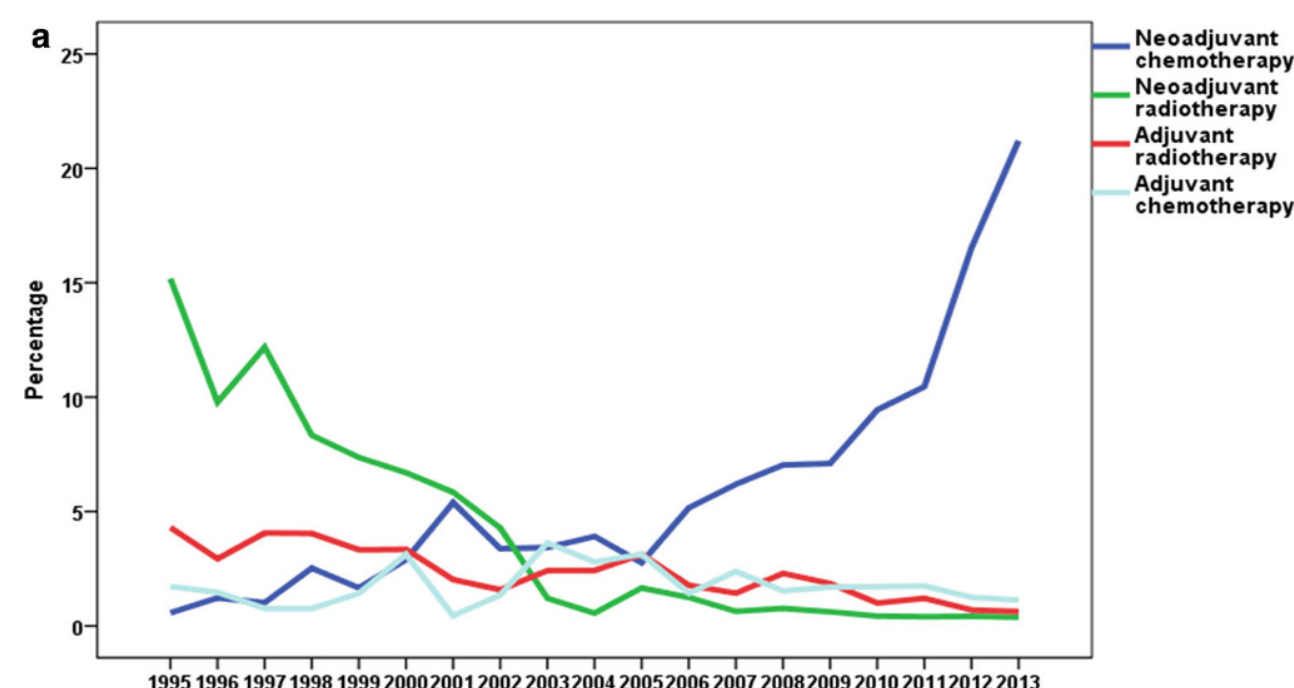

Year of radical cystectomy

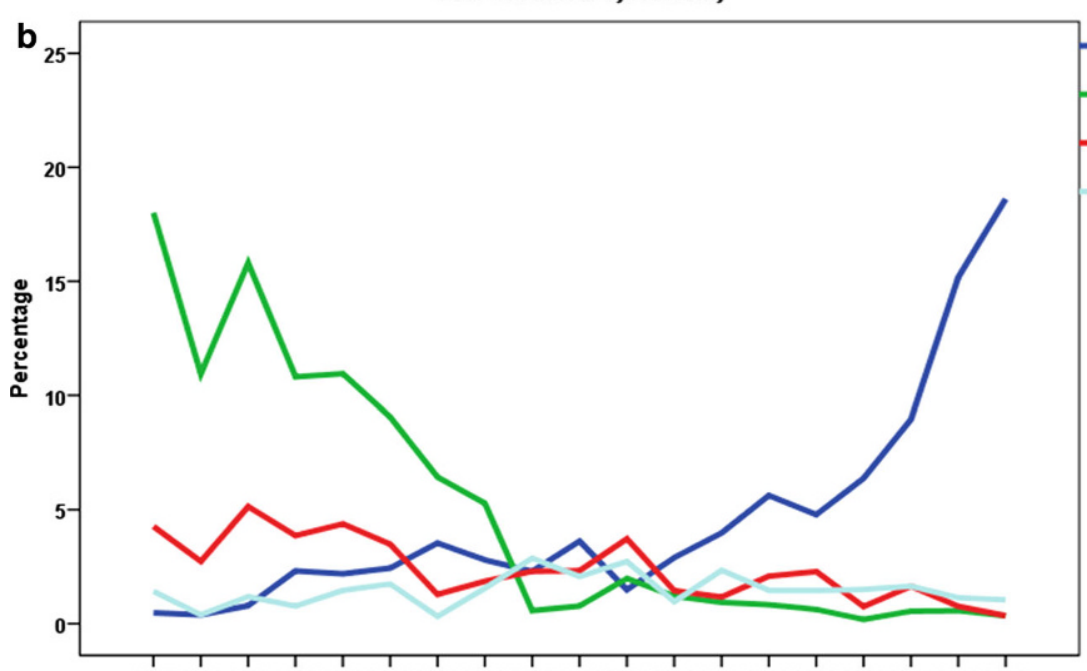

1995199619971998199920002001200220032004200520062007200820092010201120122013

Year of radical cystectomy

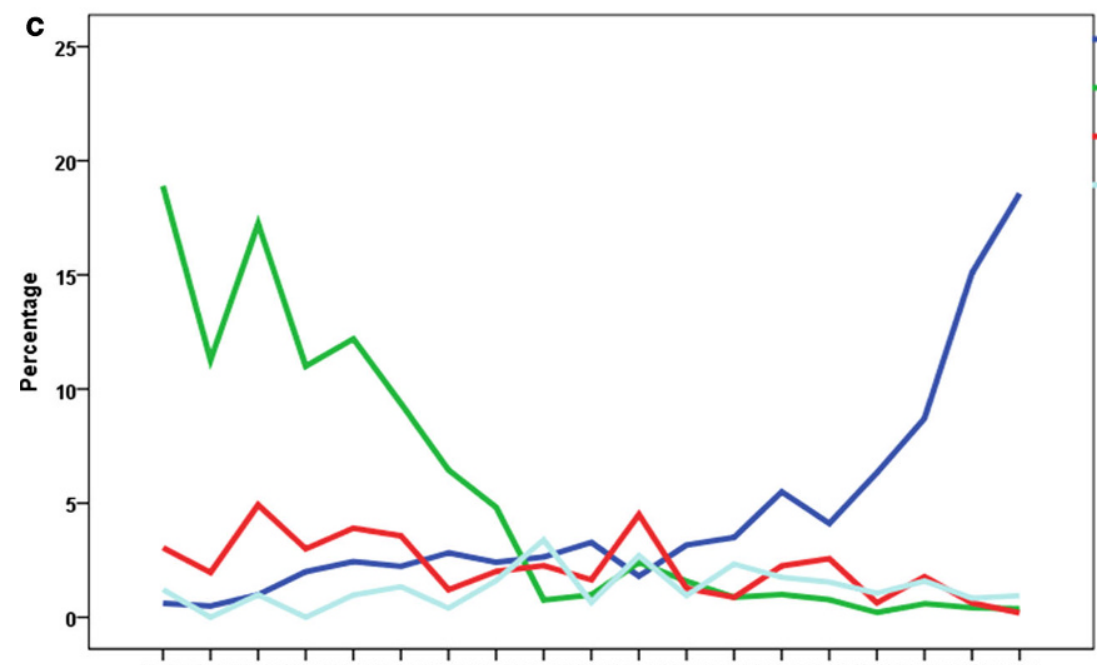

1995199619971998199920002001200220032004200520062007200820092010201120122013

Year of radical cystectomy
Neoadjuvant chemotherapy Neoadjuvant radiotherapy Adjuvant radiotherapy Adjuvant chemotherapy 
Tabel 1 Patiëntkarakteristieken van 10.338 blaaskankerpatiënten die zijn geregistreerd in de NKR, die tussen 1995 en 2013 een RC ondergingen, met of zonder perioperatieve behandeling. NB. 54 patiënten ondergingen twee vormen van perioperatieve behandelingen. De som van het aantal patiënten in subgroepen is derhalve niet gelijk aan de totale studiepopulatie [15].

\begin{tabular}{|c|c|c|c|c|c|c|c|}
\hline & $\begin{array}{l}\text { alle patiënten } \\
n=10.338\end{array}$ & $\begin{array}{l}\text { RC alleen } \\
n=8.936 \\
(86,4 \%)\end{array}$ & $\begin{array}{l}\text { RC + NAR } \\
n=330 \\
(3,2 \%)\end{array}$ & $\begin{array}{l}\text { RC + NAC } \\
n=725 \\
(7,0 \%)\end{array}$ & $\begin{array}{l}\mathrm{RC}+\mathrm{AR} \\
n=218 \\
(2,1 \%)\end{array}$ & $\begin{array}{l}\mathrm{RC}+\mathrm{AC} \\
n=183 \\
(1,8 \%)\end{array}$ & $p$-waarde \\
\hline \multicolumn{8}{|l|}{ geslacht } \\
\hline $\operatorname{man}$ & $7.753(75,0)$ & $6.726(75,3)$ & $251(76,1)$ & $533(73,5)$ & $147(67,4)$ & $129(70,5)$ & 0,202 \\
\hline vrouw & $2.582(25,0)$ & $2.210(24,7)$ & $79(23,9)$ & $192(26,5)$ & $71(32,6)$ & $54(29,5)$ & - \\
\hline \multicolumn{8}{|l|}{ leeftijd } \\
\hline $0-44$ & $293(2,8)$ & $209(2,3)$ & $17(5,2)$ & $43(5,9)$ & $9(4,1)$ & $17(9,3)$ & $<0,001$ \\
\hline $45-59$ & $2.220(21,5)$ & $1.812(20,3)$ & $77(23,3)$ & $217(29,9)$ & $57(26,1)$ & $85(46,4)$ & - \\
\hline $60-74$ & $5.863(56,7)$ & $5.093(57,0)$ & $191(57,9)$ & $400(55,2)$ & $128(58,7)$ & $78(42,6)$ & - \\
\hline $75+$ & $1.956(18,9)$ & $1.822(20,5)$ & $45(13,6)$ & $65(9,0)$ & $24(11,0)$ & $3(1,6)$ & - \\
\hline \multicolumn{8}{|l|}{ diagnose: periode } \\
\hline 1995-1999 & $1.969(19,0)$ & $1.652(18,5)$ & $205(62,1)$ & $28(3,9)$ & $73(33,5)$ & $24(13,1)$ & $<0,001$ \\
\hline 2000-2004 & $2.370(22,9)$ & $2.103(23,5)$ & $84(25,5)$ & $90(12,4)$ & $56(25,7)$ & $55(30,1)$ & - \\
\hline 2005-2009 & $3.037(29,4)$ & $2.722(30,5)$ & $29(8,8)$ & $175(24,1)$ & $63(28,9)$ & $61(33,3)$ & - \\
\hline 2010-2013 & $2.962(28,7)$ & $2.459(27,5)$ & $12(3,6)$ & $432(59,0)$ & $26(11,9)$ & $43(23,5)$ & - \\
\hline \multicolumn{8}{|c|}{ klinisch T-stadium } \\
\hline $\mathrm{cTa} / \mathrm{cTis}$ & $219(2,1)$ & $213(2,4)$ & $4(1,2)$ & $2(0,3)$ & $0(0,0)$ & $0(0,0)$ & $<0,001$ \\
\hline $\mathrm{cT} 1$ & $1.015(9,8)$ & $962(10,8)$ & $19(5,8)$ & $20(2,8)$ & $7(3,2)$ & $7(3,8)$ & - \\
\hline $\mathrm{cT} 2$ & $6.239(60,4)$ & $5.526(61,8)$ & $205(62,1)$ & $358(49,4)$ & $80(36,7)$ & $105(57,4)$ & - \\
\hline $\mathrm{cT} 3$ & $1.174(11,4)$ & $875(9,8)$ & $42(12,7)$ & $201(27,7)$ & $35(16,1)$ & $28(15,3)$ & - \\
\hline cT4 & $691(6,7)$ & $420(4,9)$ & $33(10,0)$ & $130(17,9)$ & $69(31,7)$ & $29(15,8)$ & - \\
\hline cTx & $1.000(9,7)$ & $920(10,3)$ & $27(8,2)$ & $14(1,9)$ & $27(12,4)$ & $14(7,7)$ & - \\
\hline \multicolumn{8}{|c|}{ klinisch $N$-stadium } \\
\hline $\mathrm{cN} 0$ & $7.784(75,3)$ & $6.934(77,6)$ & $261(79,1)$ & $381(52,6)$ & $148(67,9)$ & $89(48,6)$ & $<0,001$ \\
\hline $\mathrm{cN} 1$ & $464(4,5)$ & $318(3,6)$ & $9(2,7)$ & $110(15,2)$ & $12(5,5)$ & $20(10,9)$ & - \\
\hline $\mathrm{cN} 2$ & $405(3,9)$ & $196(2,2)$ & $7(2,1)$ & $161(22,2)$ & $18(8,3)$ & $35(19,1)$ & - \\
\hline $\mathrm{cN} 3$ & $19(0,2)$ & $9(0,1)$ & $1(0,3)$ & $7(1,0)$ & $0(0,0)$ & $2(1,1)$ & - \\
\hline $\mathrm{cNx}$ & $1.666(16,1)$ & $1.479(16,6)$ & $52(15,8)$ & $66(9,1)$ & $40(18,3)$ & $37(20,3)$ & - \\
\hline \multicolumn{8}{|c|}{ klinisch M-stadium } \\
\hline cM0 & $9.619(93,0)$ & $8.324(93,2)$ & $306(92,7)$ & $673(92,8)$ & $198(90,8)$ & $168(91,8)$ & $<0,001$ \\
\hline cM1 & $39(0,4)$ & $11(0,1)$ & $0(0,0)$ & $26(3,6)$ & $2(0,9)$ & $2(1,1)$ & - \\
\hline $\mathrm{cMx}$ & $680(6,6)$ & $601(6,7)$ & $24(7,3)$ & $26(3,6)$ & $18(8,3)$ & $13(7,1)$ & - \\
\hline \multicolumn{8}{|c|}{ tumorgradering (WHO 1973) [20] } \\
\hline graad 1 & $114(1,1)$ & $108(1,2)$ & $0(0,0)$ & $3(0,4)$ & $2(0,9)$ & $1(0,5)$ & $<0,001$ \\
\hline graad 2 & $985(9,5)$ & $898(10,0)$ & $31(9,4)$ & $31(4,3)$ & $16(7,3)$ & $10(5,5)$ & - \\
\hline $\operatorname{graad} 3$ & $8.584(83,0)$ & $7.387(82,7)$ & $279(84,5)$ & $626(86,3)$ & $187(85,8)$ & $155(84,7)$ & - \\
\hline graad onbekend & $665(6,3)$ & $543(6,1)$ & $20(6,1)$ & $65(9,0)$ & $13(6,0)$ & $17(9,3)$ & - \\
\hline
\end{tabular}

\section{Patiënten en methoden}

\section{De Nederlandse Kanker Registratie (NKR)}

De NKR registreert alle nieuw gediagnosticeerde maligniteiten in Nederland. Notificatie wordt verkregen via het Pathologisch-Anatomisch Landelijk Geautomatiseerd Archief (PALGA) en de Landelijke Medische Registatie (LMR) [16]. Onafhankelijke registratieassistenten van de NKR verzamelen patiënt-, tumor- en behandelingskarakteristieken uit patiëntdossiers. Topografie en morfologie worden gecodeerd volgens de Internationale Classificatie van Ziekten voor Oncologie (ICD-O) en ziektestadia volgens het TNM-classificatiesysteem [17]. In deze studie werden alle oude TNM-classificaties geconverteerd naar de meest recente versie, het $7^{\mathrm{e}} \mathrm{TNM}$-classificatiesysteem [18].

\section{De patiënten}

Uit de NKR werden alle patiënten met BK geïncludeerd die als primaire behandeling een $\mathrm{RC}$ ondergingen met curatieve intentie (cTa/is, cT1-4, cN0-3, cM0-1 [M1: alleen retrope- 
Tabel 1 Patiëntkarakteristieken van 10.338 blaaskankerpatiënten die zijn geregistreerd in de NKR, die tussen 1995 en 2013 een RC ondergingen, met of zonder perioperatieve behandeling. NB. 54 patiënten ondergingen twee vormen van perioperatieve behandelingen. De som van het aantal patiënten in subgroepen is derhalve niet gelijk aan de totale studiepopulatie [15]. (Vervolg)

\begin{tabular}{|c|c|c|c|c|c|c|c|}
\hline & $\begin{array}{l}\text { alle patiënten } \\
n=10.338\end{array}$ & $\begin{array}{l}\text { RC alleen } \\
n=8.936 \\
(86,4 \%)\end{array}$ & $\begin{array}{l}\text { RC + NAR } \\
n=330 \\
(3,2 \%)\end{array}$ & $\begin{array}{l}\text { RC + NAC } \\
n=725 \\
(7,0 \%)\end{array}$ & $\begin{array}{l}\mathrm{RC}+\mathrm{AR} \\
n=218 \\
(2,1 \%)\end{array}$ & $\begin{array}{l}\mathrm{RC}+\mathrm{AC} \\
n=183 \\
(1,8 \%)\end{array}$ & $p$-waarde \\
\hline \multicolumn{8}{|l|}{ tumorhistologie } \\
\hline urotheelcelcarcinoom & $9.527(92,2)$ & $8.249(92,3)$ & $305(92,4)$ & $680(93,8)$ & $183(83,9)$ & $160(87,4)$ & $<0,001$ \\
\hline plaveiselcelcarcinoom & $428(4,1)$ & $384(4,3)$ & $13(3,9)$ & $7(1,0)$ & $19(8,7)$ & $6(3,3)$ & - \\
\hline adenocarcinoom & $151(1,5)$ & $124(1,4)$ & $9(2,7)$ & $5(0,7)$ & $12(5,5)$ & $3(1,6)$ & - \\
\hline kleincellig carcinoom & $116(1,1)$ & $79(0,9)$ & $0(0,0)$ & $24(3,3)$ & $1(0,5)$ & $12(6,6)$ & - \\
\hline sarcoom & $46(0,4)$ & $39(0,4)$ & $2(0,6)$ & $4(0,6)$ & $1(0,5)$ & $1(0,5)$ & - \\
\hline anders/onbekend & $70(0,7)$ & $61(0,7)$ & $1(0,3)$ & $5(0,7)$ & $2(0,9)$ & $1(0,5)$ & - \\
\hline \multicolumn{8}{|c|}{ type ziekenhuis van radicale cystectomie } \\
\hline niet-opleidingsziekenhuis & $4.636(44,8)$ & $4.150(46,4)$ & $130(39,1)$ & $205(28,3)$ & $89(40,8)$ & $78(42,6)$ & $<0,001$ \\
\hline opleidingsziekenhuis & $2.839(27,5)$ & $2.421(27,1)$ & $121(36,7)$ & $218(30,1)$ & $44(20,2)$ & $47(25,7)$ & - \\
\hline academisch ziekenhuis & $1.169(11,3)$ & $970(10,9)$ & $27(8,2)$ & $122(16,8)$ & $27(12,4)$ & $30(16,4)$ & - \\
\hline AVL & $473(4,6)$ & $280(3,1)$ & $36(10,9)$ & $142(19,6)$ & $25(11,5)$ & $8(4,4)$ & - \\
\hline onbekend & $1.221(11,8)$ & $1.115(12,5)$ & $17(5,2)$ & $38(5,2)$ & $33(15,1)$ & $20(10,9)$ & - \\
\hline
\end{tabular}

$A C$ adjuvante chemotherapie, $A R$ adjuvante radiotherapie, $N A C$ neoadjuvante chemotherapie (inclusief inductiechemotherapie bij cN1-3- of cM1-ziekte), NAR neoadjuvante radiotherapie, $N K R$ Nederlandse Kanker Registratie, AVL Antoni van Leeuwenhoek, $R C$ radicale cystectomie

ritoneale lymfadenopathie], ICD-O C48.0) tussen 1995 en $2013(n=10.338)$. Patiënten die een partiële of salvagecystectomie ondergingen, werden geëxcludeerd. PB werden gecategoriseerd in NAC (of inductiechemotherapie (IC) bij cN1-3- of cM1-ziekte), NAR, AC, AR of geen PB. Specificaties betreffende toegepaste chemotherapeutica, het aantal cycli, alsmede radiatiedoseringen en schema's zijn niet geregistreerd in de NKR. Ziekenhuizen werden ingedeeld in niet-opleidingsziekenhuizen, opleidingsziekenhuizen, academische ziekenhuizen en het Nederlands Kanker Instituut (NKI), een van de tertiaire oncologiecentra in Nederland.

\section{Statistische analyses}

De trends in de toepassing van PB in een bepaalde periode werden berekend middels het aandeel patiënten dat jaarlijks NAC (inclusief IC), NAR, AC, AR of geen PB ontving. Chi-kwadraattesten werden uitgevoerd om de toepassing van PB in een bepaalde periode, alsmede tussen verschillende typen ziekenhuizen te vergelijken. Multivariabele logistische regressieanalyses werden uitgevoerd om de odds van geslacht, leeftijd, periode van diagnosestelling, cTNM-stadium, histologie, tumorgradering volgens de WHO uit 1973 [20] en type ziekenhuis op het ontvangen van PB te bepalen. Statische analyses werden uitgevoerd met SPSS statistical software (version 19.0; SPSS Inc., Chicago, III., USA). $P$-waarden werden statistisch significant beschouwd indien ze kleiner waren dan 0,05 [19].

\section{Resultaten}

Wij analyseerden het gebruik van PB bij 10.338 patiënten die een $\mathrm{RC}$ met curatieve intentie voor BK ondergingen. In het gehele cohort ontvingen $8.936(86 \%)$ patiënten geen enkele vorm van PB. In totaal ontvingen $725(7,0 \%)$ patiënten NAC (of IC), 330 (3,2\%) NAR, 183 (1,8\%) AC, en $218(2,1 \%)$ AR. $54(0,5 \%)$ patiënten ontvingen meer dan één soort PB. Patiëntkarakteristieken worden getoond in tab. 1. De toepassing van NAC (inclusief IC) steeg van $0,6 \%$ in 1995 naar $21 \%$ in $2013(p<0,001)$. Dit in tegenstelling tot de toepassing van NAR, die daalde van $15 \%$ naar $0,4 \%(p<0,001)$. Het gebruik van AC en AR was in $2013<1,5 \%$. fig. $1 a$ toont de resultaten van onze trendanalyse voor de gehele studiepopulatie. Uit subanalyses van data van patiënten die waren gestadieerd met een cT2-4 N0- of Nx M0- of Mx-tumor $(n=7.295)$ of met een cT2-4 N0 M0-tumor $(n=6.032)$, bleek dat $18,6 \%$ van deze patiënten in 2013 behandeld werd met NAC; dit was het geval in beide groepen patiënten. NAR, AR en AC werden in $\leq 1 \%$ van de gevallen toegepast (fig. $1 \mathrm{~b}$ en c). Gerekend over de hele studieperiode kreeg $3,1 \%$ van de patiënten met pT3-4- en/of pN1-3-ziekte $(n=5.545)$ AC toegediend. In 2013 was dit het geval bij 1,9\% van de patiënten.

Multivariabele logistische regressieanalyse toonde dat vrouwen, jongere patiënten en patiënten met uitgebreidere ziektestadia, $\geq \mathrm{cT} 3$ (in vergelijking met T2), $\geq \mathrm{cN} 1$, cM1 (retroperitoneale lymfadenopathie), een hogere kans hadden om NAC of IC te ontvangen. Urotheelcelcarcinoom (UC) was aanwezig bij 9.527 (92\%) patiënten. In vergelijking met UC-patiënten, was de kans op het ontvangen van 
Tabel 2 Patiëntkarakteristieken [15].

\begin{tabular}{|c|c|c|c|c|c|c|c|c|}
\hline \multicolumn{2}{|c|}{ patiëntkarakteristieken } & \multirow{2}{*}{$\begin{array}{l}\begin{array}{l}\text { alle patiën- } \\
\text { ten }\end{array} \\
10.338\end{array}$} & \multirow{2}{*}{$\begin{array}{l}\operatorname{man} \\
7.753\end{array}$} & \multirow{2}{*}{$\begin{array}{l}\text { vrouw } \\
2.582\end{array}$} & \multirow{2}{*}{$\begin{array}{l}0-44 \\
293\end{array}$} & \multirow{2}{*}{$\begin{array}{l}45-59 \mathrm{jr} \\
2.220\end{array}$} & \multirow{2}{*}{$\begin{array}{l}60-74 \mathrm{jr} \\
5.863\end{array}$} & \multirow{2}{*}{$\begin{array}{l}75+\mathrm{jr} \\
1.956\end{array}$} \\
\hline alle patiënten & $n$ & & & & & & & \\
\hline & $\begin{array}{l}\text { NAC of IC: } n \\
\text { (\% subcat) }\end{array}$ & $725(7,0)$ & $533(6,9)$ & $192(7,4)$ & $43(14,7)$ & $217(9,8)$ & $400(6,8)$ & $65(3,3)$ \\
\hline & OR & - & ref & 1,23 & 2,33 & 1,44 & ref & 0,43 \\
\hline & $95 \%-B I$ & - & - & $1,00-1,50$ & $1,52-3,57$ & $1,17-1,76$ & - & $0,32-0,57$ \\
\hline \multirow{4}{*}{$\begin{array}{l}\text { cT2-4a, N0 } \\
\text { of Nx, M0 of } \\
M x\end{array}$} & $n$ & 7.295 & 5.455 & 1.840 & 174 & 1.561 & 4.148 & 1.412 \\
\hline & $\begin{array}{l}\text { NAC: } n(\% \\
\text { subcat })\end{array}$ & $420(5,8)$ & $310(5,7)$ & $110(6,0)$ & $26(14,9)$ & $128(8,2)$ & $222(5,4)$ & $44(3,1)$ \\
\hline & OR & - & ref & 1,21 & 3,68 & 1,58 & ref & 0,46 \\
\hline & $95 \%-B I$ & - & - & $0,94-1,54$ & $2,21-6,15$ & $1,24-2,02$ & - & $0,32-0,64$ \\
\hline \multirow{4}{*}{$\begin{array}{l}\text { cT2-4a N0 } \\
\text { M0 }\end{array}$} & $n$ & 6.032 & 4.512 & 1.519 & 135 & 1.296 & 3.445 & 1.156 \\
\hline & $\begin{array}{l}\text { NAC: } n(\% \\
\text { subcat })\end{array}$ & $358(5,9)$ & $262(5,8)$ & $96(6,3)$ & $20(14,8)$ & $115(8,9)$ & $185(9,5)$ & $38(3,3)$ \\
\hline & OR & - & ref & 1,15 & 3,22 & 1,71 & ref & 0,49 \\
\hline & $95 \%-\mathrm{BI}$ & - & - & $0,88-1,50$ & $1,78-5,80$ & $1,31-2,22$ & - & $0,34-0,72$ \\
\hline \multirow{4}{*}{$\begin{array}{l}\text { cTany N1-3 } \\
\text { en/of cM1 }\end{array}$} & $n$ & 892 & 622 & 270 & 49 & 240 & 483 & 120 \\
\hline & $\begin{array}{l}\text { IC: } n(\% \text { sub- } \\
\text { cat })\end{array}$ & $279(31,3)$ & $203(32,6)$ & $76(28,1)$ & $14(28,6)$ & $84(35,0)$ & $164(34,0)$ & $17(14,2)$ \\
\hline & OR & - & ref & 0,82 & 0,89 & 1,15 & ref & 0,3 \\
\hline & $95 \%$-BI & - & - & $0,54-1,24$ & $0,37-2,11$ & $0,76-1,76$ & - & $0,16-0,57$ \\
\hline
\end{tabular}

Tabel 3 Diagnoseperiode [15].

\begin{tabular}{|c|c|c|c|c|c|}
\hline \multicolumn{2}{|l|}{ diagnoseperiode } & \multirow{2}{*}{$\begin{array}{l}1995-1999 \\
1.969\end{array}$} & \multirow{2}{*}{$\begin{array}{l}2000-2004 \\
2.370\end{array}$} & \multirow{2}{*}{$\begin{array}{l}2005-2009 \\
3.037\end{array}$} & \multirow{2}{*}{$\begin{array}{l}2010-2013 \\
2.962\end{array}$} \\
\hline alle patiënten & $n$ & & & & \\
\hline & $\begin{array}{l}\text { NAC of IC: } n \\
\text { (\% subcat) }\end{array}$ & $28(1,4)$ & $90(3,8)$ & $175(5,8)$ & $432(14,6)$ \\
\hline & OR & 0,22 & 0,54 & ref & 3,67 \\
\hline & $95 \%-B I$ & $0,32-0,36$ & $0,40-0,74$ & - & $2,96-4,56$ \\
\hline \multirow{4}{*}{$\begin{array}{l}\text { cT2 }-4 a, N 0 \text { of } \\
\mathrm{Nx}, \mathrm{M} 0 \text { of } \mathrm{Mx}\end{array}$} & $n$ & 1.253 & 1.655 & 2.205 & 2.182 \\
\hline & $\begin{array}{l}\text { NAC: } n(\% \\
\text { subcat })\end{array}$ & $16(1,3)$ & $49(3,0)$ & $85(3,9)$ & $270(12,4)$ \\
\hline & OR & 0,21 & 0,55 & ref & 4,12 \\
\hline & $95 \%-B I$ & $0,12-0,39$ & $0,37-0,83$ & - & $3,15-5,40$ \\
\hline \multirow[t]{4}{*}{ cT2-4a N0 M0 } & $n$ & 976 & 1.291 & 1.781 & 1.984 \\
\hline & $\begin{array}{l}\text { NAC: } n(\% \\
\text { subcat })\end{array}$ & $13(1,3)$ & $35(2,7)$ & $66(3,7)$ & $244(12,3)$ \\
\hline & OR & 0,24 & 0,53 & ref & 4,34 \\
\hline & $95 \%-\mathrm{BI}$ & $0,12-0,48$ & $0,34-0,85$ & - & $3,23-5,84$ \\
\hline \multirow{4}{*}{$\begin{array}{l}\text { cTany N1-3 } \\
\text { en/of cM1 }\end{array}$} & $n$ & - & 193 & 297 & 317 \\
\hline & IC: $n$ (\% subcat) & $7(8,2)$ & $35(18,1)$ & $83(27,9)$ & $144(48,6)$ \\
\hline & OR & 0,15 & 0,44 & ref & 3,1 \\
\hline & $95 \%-\mathrm{BI}$ & $0,05-0,47$ & $0,25-0,79$ & - & $2,03-4,70$ \\
\hline
\end{tabular}

NAC groter bij patiënten met kleincellige carcinomen en sarcomen en lager bij patiënten met adeno- of plaveiselcelcarcinomen. RC werd het vaakst uitgevoerd in niet-opleidingsziekenhuizen (45\%). Indien RC werd uitgevoerd in niet-opleidingsziekenhuizen, was de kans op het ontvangen van NAC verlaagd. In academische ziekenhuizen werd RC het vaakst toegepast en met name het NKI. In 2013 was de toepassing van NAC of IC gestegen tot $20 \%$ in niet-opleidingsziekenhuizen, tot $24 \%$ in academische ziekenhuizen en tot $49 \%$ in het NKI. De toepassing van NAC in opleidingsziekenhuizen bleef achter met $18 \%(p=0,001)$. De resultaten van de multivariabele regressieanalyses van de data van patiënten met BK cT2-4, N0 of Nx, M0 of Mx en cT2-4 N0 M0 waren vergelijkbaar. Bij patiënten die wa- 
Hier staat een advertentie.

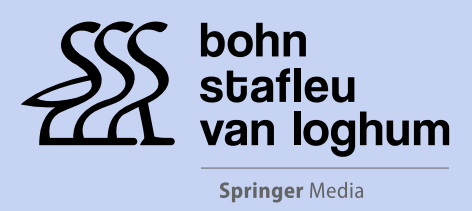

Houten 2017 
Hier staat een advertentie.

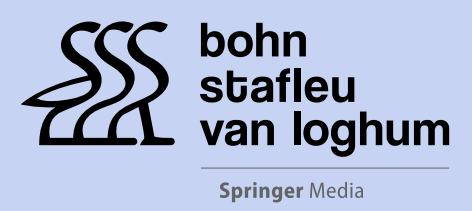

Houten 2017 
Tabel 4 Klinisch T-stadium[15].

\begin{tabular}{|c|c|c|c|c|c|c|c|}
\hline \multicolumn{2}{|c|}{ klinisch T-stadium } & \multirow{2}{*}{$\begin{array}{l}\mathrm{cTa} / \mathrm{cTis} \\
219\end{array}$} & \multirow{2}{*}{$\begin{array}{l}\mathrm{cT} 1 \\
1.015\end{array}$} & \multirow{2}{*}{$\frac{\mathrm{cT} 2}{6.239}$} & \multirow{2}{*}{$\begin{array}{l}\text { cT3 } \\
1.174\end{array}$} & \multirow{2}{*}{$\frac{\mathrm{cT} 4}{691}$} & \multirow{2}{*}{$\frac{\mathrm{cTx}}{1.000}$} \\
\hline alle & $n$ & & & & & & \\
\hline patiënten & $\begin{array}{l}\text { NAC of IC: } n \\
\text { (\% subcat) }\end{array}$ & $2(0,9)$ & $20(2,0)$ & $358(5,7)$ & $201(17,1)$ & $130(18,8)$ & $14(1,4)$ \\
\hline & OR & 0,12 & 0,32 & ref & 2,44 & 3,02 & 0,34 \\
\hline & $95 \%-\mathrm{BI}$ & $0,03-0,48$ & $0,20-0,51$ & - & $1,96-3,04$ & $2,32-3,95$ & $0,18-0,63$ \\
\hline \multirow{4}{*}{$\begin{array}{l}\text { cT2-4a, N0 } \\
\text { of Nx, M0 } \\
\text { of Mx }\end{array}$} & $n$ & - & - & 5.819 & 941 & 535 & - \\
\hline & $\begin{array}{l}\text { NAC: } n(\% \\
\text { subcat })\end{array}$ & - & - & $241(4,1)$ & $110(11,7)$ & $69(12,9)$ & - \\
\hline & OR & - & - & ref & 3,05 & 3,97 & - \\
\hline & $95 \%-\mathrm{BI}$ & - & - & - & $2,36-3,95$ & $2,89-5,44$ & - \\
\hline \multirow{4}{*}{$\begin{array}{l}\text { cT2-4a N0 } \\
\text { M0 }\end{array}$} & $n$ & - & - & 4.801 & 802 & 429 & - \\
\hline & $\begin{array}{l}\text { NAC: } n(\% \\
\text { subcat })\end{array}$ & - & - & $201(4,2)$ & $96(12,0)$ & $61(14,2)$ & - \\
\hline & OR & - & - & ref & 3,14 & 4,31 & - \\
\hline & $95 \%-\mathrm{BI}$ & - & - & - & $2,38-4,16$ & $3,06-6,07$ & - \\
\hline \multirow{4}{*}{$\begin{array}{l}\text { cTany } \\
\text { N1-3 en/of } \\
\text { cM1 }\end{array}$} & $n$ & - & 43 & 420 & 233 & 156 & 40 \\
\hline & IC: $n$ (\% subcat) & - & $8(18,6)$ & $117(27,9)$ & $91(39,1)$ & $61(39,1)$ & $2(5,0)$ \\
\hline & OR & - & 0,6 & ref & 1,52 & 1,86 & 0,28 \\
\hline & $95 \%-\mathrm{BI}$ & - & $0,23-1,52$ & - & $0,99-2,31$ & $1,12-3,10$ & $0,06-1,34$ \\
\hline
\end{tabular}

ren gestadieerd met cN1-3- en/of cM1-BK $(n=892)$ werd IC toegepast in $31 \%$ van de gevallen. IC werd het vaakst toegepast in het NKI. De mediane leeftijd van de totale populatie per type ziekenhuis was significant verschillend. In niet-opleidings-, opleidings- en academische ziekenhuizen en het NKI-AVL bedroeg deze respectievelijk 68, 67, 65 en 62 jaar $(p<0,001)$.

In de tabellen 2-8 staan de resultaten van de multivariabele regressieanalyse naar de samenhang tussen patiënt-, tumor- en ziekenhuiskarakteristieken en de toepassing van neoadjuvante en inductiechemotherapie bij alle blaaskankerpatiënten die zijn geregistreerd in de NKR die tussen 1995 en 2013 een radicale cystectomie ondergingen [15].

Bij patiënten met cT2-4 N0 M0-ziekte was de toepassing van NAR significant geassocieerd met een eerder in de tijd gelegen jaar waarin de diagnose was gesteld en met behandeling in academische, opleidingsziekenhuizen en het NKI. Bij patiënten met pT3-4- en/of pN1-3-ziekte werd AC significant meer toegepast bij jongere patiënten ( $<75$ jaar), hogere $\mathrm{pN}$-stadia ( $\mathrm{pN} 2-3$ ) en bij patiënten met kleincellige carcinomen. AR werd vroeger significant meer toegepast dan tegenwoordig bij jongere patiënten, bij patiënten met pT4- en pN1-ziekte, bij patiënten met adeno- of plaveiselcelcarcinomen en in het NKI. Andere patiëntkarakteristieken, behoudens bovengenoemde, waren niet significant gerelateerd aan de toepassing van NAR, AC en AR.

\section{Discussie}

In deze trendanalyse evalueerden wij het gebruik van $\mathrm{PB}$ en RC in Nederland. Onze resultaten tonen belangrijke kenteringen inzake PB in de laatste twee decennia. De stijgende lijn bij NAC en de dalende lijn bij NAR, AR en AC representeren de langzame, maar gestage adaptatie van internationale richtlijnen in de huidige praktijk in Nederland.

Op basis van gedateerde, alsmede op basis van data van lagere kwaliteit is de rol van NAR en AR aangaande overlevingswinst beperkt en wordt toepassing niet aanbevolen [2, 21]. In Nederland is de toepassing van NAR en AR in 2013 gedaald tot $<1 \%$. Wat opvalt in onze resultaten is dat NAR vóór 2000 als PB voorkeur genoot. Een mogelijke verklaring hiervoor is dat de landmarkstudie van Grossman et al. [7] aangaande NAC pas in 2003 werd gepubliceerd.

Prospectieve studies laten zien dat multimodale blaassparende therapieën met moderne en geavanceerde radiotherapeutische technieken dezelfde resultaten kunnen bereiken als RC alleen [22, 23]. Hiernaar zijn geen RCT's verricht. Vandaag de dag wordt er zelfs door sommigen geopperd dat de huidige radiotherapeutische technieken eenzelfde bijdrage kunnen leveren in de neoadjuvante of adjuvante setting [24]. Zo her-evalueerden Granfors et al. [25] retrospectief de huidige rol van NAR. In 187 achtereenvolgende patiënten die behandeld werden voor cT1-3-BK toonden zij een CD (pT0) aan bij zeven van 97 (7\%) patiënten die waren behandeld met RC, versus 51 van 90 (57\%) patiënten die NAR ondergingen. Dit effect was vooral aanwezig bij patiënten met cT3-tumoren (CD in $0 \%$ vs. $56 \%$ ) en re- 
Tabel 5 Klinisch N- en M-stadium [15].

\begin{tabular}{|c|c|c|c|c|c|c|c|c|c|}
\hline \multicolumn{2}{|c|}{ klinisch N- of M-stadium } & \multirow{2}{*}{$\begin{array}{l}\mathrm{cN0} \\
7.784\end{array}$} & \multirow{2}{*}{$\begin{array}{l}\mathrm{cN} 1 \\
464\end{array}$} & \multirow{2}{*}{$\begin{array}{l}\frac{\mathrm{cN} 2}{405} \\
\end{array}$} & \multirow{2}{*}{$\frac{\mathrm{cN} 3}{19}$} & \multirow{2}{*}{$\begin{array}{l}\mathrm{cNx} \\
1.666\end{array}$} & \multirow{2}{*}{$\begin{array}{l}\mathrm{cM} 0 \\
9.619\end{array}$} & \multirow{2}{*}{$\begin{array}{l}\mathrm{cM} 1 \\
39\end{array}$} & \multirow{2}{*}{$\begin{array}{l}\mathrm{cMx} \\
680\end{array}$} \\
\hline$\overline{\text { alle }}$ & $\bar{n}$ & & & & & & & & \\
\hline patiënten & $\begin{array}{l}\text { NAC of IC: } n \\
\text { (\% subcat) }\end{array}$ & $381(4,9)$ & $\begin{array}{l}110 \\
(23,7)\end{array}$ & $\begin{array}{l}161 \\
(39,8)\end{array}$ & $7(36,8)$ & $66(4,0)$ & $673(7,0)$ & $26(66,7)$ & $26(3,8)$ \\
\hline & OR & ref & 4,59 & 7,71 & 3,68 & 1,31 & ref & 4,1 & 0,95 \\
\hline & $95 \%-\mathrm{BI}$ & - & $3,47-6,06$ & $5,87-10,13$ & $1,26-10,73$ & $0,97-1,75$ & - & $1,89-8,88$ & $0,59-1,55$ \\
\hline \multirow{4}{*}{$\begin{array}{l}\text { cT2-4a, } \\
\text { N0 of Nx, } \\
\text { M0 of Mx }\end{array}$} & $n$ & 6.258 & - & - & - & 1.037 & 6.938 & - & 357 \\
\hline & $\begin{array}{l}\text { NAC: } n(\% \\
\text { subcat })\end{array}$ & $365(5,8)$ & - & - & - & $55(5,3)$ & $409(5,9)$ & - & $11(3,1)$ \\
\hline & OR & ref & - & - & - & 1,27 & ref & - & 0,89 \\
\hline & $95 \%-\mathrm{BI}$ & - & - & - & - & $0,93-1,74$ & - & - & $1,05-2,02$ \\
\hline \multirow{4}{*}{$\begin{array}{l}\text { cT2-4a N0 } \\
\text { M0 }\end{array}$} & $n$ & 6.032 & - & - & - & - & 6.032 & - & - \\
\hline & $\begin{array}{l}\text { NAC: } n(\% \\
\text { subcat })\end{array}$ & $358(5,9)$ & - & - & - & - & $358(5,9)$ & - & - \\
\hline & OR & - & - & - & - & - & - & - & - \\
\hline & $95 \%-\mathrm{BI}$ & - & - & - & - & - & - & - & - \\
\hline \multirow{4}{*}{$\begin{array}{l}\text { cTany } \\
\text { N1-3 en/of } \\
\text { cM1 }\end{array}$} & $n$ & - & 464 & 405 & 19 & 4 & 799 & 39 & 54 \\
\hline & $\begin{array}{l}\text { IC: } n(\% \text { sub- } \\
\text { cat) }\end{array}$ & - & $\begin{array}{l}110 \\
(23,7)\end{array}$ & $\begin{array}{l}161 \\
(39,8)\end{array}$ & $7(36,8)$ & $1(25,0)$ & $\begin{array}{l}241 \\
(30,2)\end{array}$ & $26(66,7)$ & $12(22,2)$ \\
\hline & OR & - & ref & 1,9 & 0,82 & 0,08 & ref & 3,85 & 1,38 \\
\hline & $95 \%-\mathrm{BI}$ & - & - & $1,32-2,75$ & $0,27-2,50$ & $0,00-1,39$ & - & $1,60-9,22$ & $0,63-3,05$ \\
\hline
\end{tabular}

Tabel 6 Tumorgradering volgens de WHO-gradering uit 1973 [15, 19, 20].

\begin{tabular}{|c|c|c|c|c|c|}
\hline \multicolumn{2}{|c|}{ tumorgradering (WHO 1973) } & \multirow{2}{*}{$\begin{array}{l}\text { graad } 1 \\
114\end{array}$} & \multirow{2}{*}{$\begin{array}{l}\text { graad } 2 \\
985\end{array}$} & \multirow{2}{*}{$\begin{array}{l}\text { graad 3 } \\
8.584\end{array}$} & \multirow{2}{*}{$\begin{array}{l}\text { graad onbekend } \\
665\end{array}$} \\
\hline alle patiënten & $n$ & & & & \\
\hline & $\begin{array}{l}\text { NAC of IC: } n(\% \\
\text { subcat) }\end{array}$ & $3(2,6)$ & $31(3,1)$ & $626(7,3)$ & $65(9,8)$ \\
\hline & OR & ref & 0,63 & 0,82 & 1,7 \\
\hline & $95 \%-\mathrm{BI}$ & - & $0,17-2,36$ & $0,23-2,90$ & $0,46-6,23$ \\
\hline \multirow{4}{*}{$\begin{array}{l}\text { cT2-4a, N0 of } \\
\text { Nx, M0 of Mx }\end{array}$} & $n$ & 50 & 633 & 6.300 & 312 \\
\hline & NAC: $n$ (\% subcat) & $2(4,0)$ & $17(2,7)$ & $364(5,8)$ & $37(11,9)$ \\
\hline & OR & ref & 0,44 & 0,59 & 1,51 \\
\hline & $95 \%$-BI & - & $0,09-2,10$ & $0,13-2,62$ & $0,32-7,16$ \\
\hline \multirow[t]{4}{*}{ cT2-4a N0 M0 } & $n$ & 38 & 508 & 5.242 & 244 \\
\hline & NAC: $n$ (\% subcat) & $1(2,6)$ & $13(2,6)$ & $313(6,0)$ & $31(12,7)$ \\
\hline & OR & ref & 0,73 & 1,1 & 2,92 \\
\hline & $95 \%-\mathrm{BI}$ & - & $0,09-6,14$ & $0,14-8,63$ & $0,35-24,2$ \\
\hline \multirow{4}{*}{$\begin{array}{l}\text { cTany N1-3 } \\
\text { en/of cM1 }\end{array}$} & $n$ & 4 & 72 & 762 & 54 \\
\hline & IC: $n$ (\% subcat) & $1(25,0)$ & $14(19,4)$ & $242(31,8)$ & $22(40,7)$ \\
\hline & OR & ref & 1,62 & 1,29 & 1,93 \\
\hline & $95 \%$-BI & - & $0,08-32,3$ & $0,07-23,8$ & $0,10-37,4$ \\
\hline
\end{tabular}

sulteerde in een toename van de ziektespecifieke overleving [25].

Het dient echter benadrukt te worden dat resultaten die zijn verkregen middels multimodale blaassparende therapieën met $\mathrm{CBCC}$, en met name moderne radiotherapeutische technieken, niet zonder meer vergeleken kunnen worden met RC in combinatie met perioperatieve radiotherapie. In de laatste groep zal de behandeling lokaal blijven en zal micrometastatische ziekte op afstand onberoerd blijven zon- der toepassing van CBCC. De toepassing van NAR en AR wordt niet geadviseerd in huidige richtlijnen [21].

In deze landelijke studie tonen wij aan dat de toediening van AC daalde tot $1,1 \%$ in 2013. De EORTC 30994 trial, alsmede andere RCT's aangaande AC, toonden geen overlevingsvoordeel voor directe $v s$. uitgestelde chemotherapie bij patiënten met pT3-4- of N1-3 M0-BK [3, 26]. Hoewel de power laag was ten gevolge van een trage en minimale inclusie van patiënten (284 van de 660 geplande), toonde 
Tabel 7 Tumorhistologie [15].

\begin{tabular}{|c|c|c|c|c|c|c|c|}
\hline tumorhistologie & & $\begin{array}{l}\text { urotheel- } \\
\text { celcarcinoom }\end{array}$ & $\begin{array}{l}\text { plaveisel- } \\
\text { celcarinoom }\end{array}$ & $\begin{array}{l}\text { adeno- } \\
\text { carcinoom }\end{array}$ & $\begin{array}{l}\text { kleincellig } \\
\text { carcinoom }\end{array}$ & sarcoom & $\begin{array}{l}\text { anders/ } \\
\text { onbekend }\end{array}$ \\
\hline \multirow[t]{4}{*}{ alle patiënten } & $n$ & 9.527 & 428 & 151 & 116 & 46 & 70 \\
\hline & $\begin{array}{l}\text { NAC of IC: } n \\
\text { (\% subcat) }\end{array}$ & $680(7,1)$ & $7(1,6)$ & $5(3,3)$ & $24(20,7)$ & $4(8,7)$ & $5(7,1)$ \\
\hline & OR & ref & 0,1 & 0,26 & 2,39 & 3,87 & 0,71 \\
\hline & $95 \%-\mathrm{BI}$ & - & $0,04-0,23$ & $0,10-0,72$ & $1,37-4,16$ & $1,04-14,38$ & $0,24-2,09$ \\
\hline \multirow{4}{*}{$\begin{array}{l}\text { cT2-4a, N0 of } \\
\text { Nx, M0 of } \\
\mathrm{Mx}\end{array}$} & $n$ & 6.752 & 318 & 97 & 88 & - & 40 \\
\hline & $\begin{array}{l}\text { NAC: } n(\% \\
\text { subcat })\end{array}$ & $393(5,8)$ & $5(1,6)$ & $3(3,1)$ & $16(18,2)$ & - & $3(7,5)$ \\
\hline & OR & ref & 0,15 & 0,17 & 1,9 & - & 0,81 \\
\hline & $95 \%-\mathrm{BI}$ & - & $0,06-0,38$ & $0,05-0,60$ & $0,97-3,74$ & - & $0,23-2,84$ \\
\hline \multirow{4}{*}{$\begin{array}{l}\text { cT2-4a N0 } \\
\text { M0 }\end{array}$} & $n$ & 5.580 & 258 & 81 & 79 & - & 34 \\
\hline & $\begin{array}{l}\text { NAC: } n(\% \\
\text { subcat })\end{array}$ & $333(6,0)$ & $5(1,9)$ & $3(3,7)$ & $15(20,0)$ & - & $2(5,9)$ \\
\hline & OR & ref & 0,22 & 0,2 & 2,28 & - & 0,56 \\
\hline & $95 \%$-BI & - & $0,08-0,55$ & $0,05-0,74$ & $1,11-4,65$ & - & $0,12-2,55$ \\
\hline \multirow{4}{*}{$\begin{array}{l}\text { cTany N1-3 } \\
\text { en/of cM1 }\end{array}$} & $n$ & 818 & 43 & 9 & 12 & 2 & 8 \\
\hline & $\begin{array}{l}\text { IC: } n(\% \text { sub- } \\
\text { cat) }\end{array}$ & $269(32,9)$ & $2(4,7)$ & $2(22,2)$ & $4(33,3)$ & $1(50,0)$ & $1(12,5)$ \\
\hline & OR & ref & 0,04 & 0,92 & 0,78 & 68,8 & 0,11 \\
\hline & $95 \%-B I$ & - & $0,01-0,19$ & $0,10-9,10$ & $0,21-2,92$ & $1,78-2.664$ & $0,01-1,58$ \\
\hline
\end{tabular}

Tabel 8 Type ziekenhuis waar de radicale cystectomie plaatsvond [15].

\begin{tabular}{|c|c|c|c|c|c|c|}
\hline \multicolumn{2}{|c|}{ type ziekenhuis van radicale cystectomie } & \multirow{2}{*}{$\begin{array}{l}\begin{array}{l}\text { niet-opleidings- } \\
\text { ziekenhuis }\end{array} \\
4.636\end{array}$} & \multirow{2}{*}{$\begin{array}{l}\begin{array}{l}\text { opleidings- } \\
\text { ziekenhuis }\end{array} \\
2.839\end{array}$} & \multirow{2}{*}{$\begin{array}{l}\begin{array}{l}\text { academisch } \\
\text { ziekenhuis }\end{array} \\
1.169\end{array}$} & \multirow{2}{*}{$\begin{array}{l}\text { NKI-AVL } \\
473\end{array}$} & \multirow{2}{*}{$\begin{array}{l}\text { onbekend } \\
1.221\end{array}$} \\
\hline alle patiënten & $n$ & & & & & \\
\hline & $\begin{array}{l}\text { NAC of IC: } n(\% \\
\text { subcat) }\end{array}$ & $205(4,4)$ & $218(7,7)$ & $122(10,4)$ & $142(30,0)$ & $38(3,1)$ \\
\hline & OR & ref & 1,38 & 1,78 & 7,05 & - \\
\hline & $95 \%-\mathrm{BI}$ & - & $1,11-1,72$ & $1,37-2,32$ & $5,24-9,47$ & - \\
\hline \multirow{4}{*}{$\begin{array}{l}\text { cT2-4a, N0 of Nx, } \\
\text { M0 of Mx }\end{array}$} & $n$ & 3.318 & 2.041 & 833 & 315 & 788 \\
\hline & NAC: $n(\%$ subcat $)$ & $131(3,9)$ & $123(6,0)$ & $83(10,0)$ & $57(18,1)$ & 26 \\
\hline & OR & ref & 3,13 & 2,01 & 4,77 & - \\
\hline & $95 \%-\mathrm{BI}$ & - & $1,84-5,31$ & $1,48-2,74$ & $3,26-6,98$ & - \\
\hline \multirow[t]{4}{*}{ cT2-4a N0 M0 } & $n$ & 2.709 & 1.702 & 693 & 283 & 645 \\
\hline & NAC: $n$ (\% subcat) & $114(4,2)$ & $99(5,8)$ & $70(10,1)$ & $56(19,8)$ & $19(2,9)$ \\
\hline & OR & ref & 1,18 & 2,03 & 5,1 & - \\
\hline & $95 \%-\mathrm{BI}$ & - & $0,88-1,57$ & $1,46-2,83$ & $3,43-7,59$ & - \\
\hline \multirow{4}{*}{$\begin{array}{l}\text { cTany N1-3 en/of } \\
\text { cM1 }\end{array}$} & $n$ & 335 & 271 & 115 & 101 & 70 \\
\hline & IC: $n$ (\% subcat) & $63(18,8)$ & $95(35,1)$ & $35(30,4)$ & $83(82,2)$ & $3(4,3)$ \\
\hline & OR & ref & 2,08 & 1,43 & 27,1 & 0,67 \\
\hline & $95 \%-\mathrm{BI}$ & - & $1,36-3,17$ & $0,83-2,48$ & $13,2-55,7$ & $0,18-2,52$ \\
\hline
\end{tabular}

voorgenoemde studie na vijf jaar een progressievrij overlevingsvoordeel van $49 \%$ vs. $30 \%$ voor patiënten die wel vs. niet direct $\mathrm{AC}$ ondergingen. Dit vertaalde zich in een mediaan progressievrij overlevingsvoordeel van twee jaar [26]. Een grote beperking betreft dat minstens een op de drie patiënten die een RC ondergaat, niet meer in staat is $\mathrm{AC}$ te ontvangen, vanwege postoperatieve problemen, zoals een verminderde lichamelijke conditie en/of achteruitgang van de nierfunctie [14]. In tegenstelling tot onze landelijke data is het opvallend dat een recente analyse van de National Cancer Data Base Registry in de Verenigde Staten aantoont dat daar het gebruik van AC met $21 \%$ stabiel bleef [10]. Alles in ogenschouw nemend, laat de toepassing van $\mathrm{AC}$ ruimte voor discussie. Volgens huidige richtlijnen kan toepassing overwogen worden bij patiënten met pT3-4en/of pN1-3-BK indien NAC niet werd toegepast [19]. 
Onze data laten zien dat de toepassing van NAC in opkomst is in alle type ziekenhuizen en het gebruik voor de totale populatie is toegenomen van $0,6 \%$ in 1995 naar $21 \%$ in 2013. Dit is in overeenstemming met de National Cancer Data Base Registry analyse van Reardon et al. [10]. In 2010 werd NAC aldaar gebruikt bij $21 \%$ van de patiënten die waren gestadieerd met cT2-4 N0 M0-ziekte. De gebruikte inclusiecriteria voor NAC waren conform huidige richtlijnen [21]. In ons cohort ontving $6 \%$ van de patiënten met cT2-4 N0 M0-BK NAC (19\% in 2013). Toediening werd echter niet beperkt tot cN0 M0-ziekte, aangezien $31 \%$ van de patiënten met $\mathrm{cN1}$-3- en/of cM1-BK ook NAC (= IC) ontving. Bij cT2-4 N0 M0-BK is het gebruik van NAC geassocieerd met een lagere incidentie van occulte lymfekliermetastasen ten tijde van RC [27]. Mogelijk kunnen zo ook metastasen bij patiënten met $\mathrm{cN} 1-3-$ of $\mathrm{cM} 1-\mathrm{BK}$ gereduceerd of geëlimineerd worden. In een groep patiënten met cN1-3-BK resulteerde de toediening van IC bij $48 \%$ van de patiënten in een complete pathologische nodale respons [28]. Of de toepassing van IC ook overlevingsvoordeel oplevert, is echter niet bekend (geen RCT's beschikbaar) en kan daarom betwist worden. De behandeling van ouderen met SIBC moet nader worden belicht. Recente studieresultaten wekken de indruk dat de toepassing van RC bij ouderen onderbenut is [29]. Bovendien laten onze resultaten, alsmede die van Reardon et al. zien NAC bij ouderen zeer weinig wordt gebruikt. Bamias et al. [30] toonden aan dat chemotherapie op basis van platinum door ouderen met lokaal uitgebreide, gemetastaseerde of recidiverende ziekte in gelijke mate getolereerd werd als door jongere patiënten, indien voldaan werd aan standaard inclusiecriteria voor de toepassing van chemotherapie. In 2013 werd NAC iets vaker toegepast in academische ziekenhuizen. Waarschijnlijk zullen de huidige aanmoedigingen voor centralisatie van de behandeling van het SIBC door experts en overheden/ overheidsinstanties in de toekomst meer prominent worden, indien verschillen in de toepassing van evidencebased richtlijnen persisteren [30, 31].

In vergelijking met de toepassing van perioperatieve chemotherapie bij de behandeling van andere maligniteiten, is de toepassing bij BK-patiënten aanzienlijk lager. Bijvoorbeeld, in Nederland ontvangt meer dan $60 \%$ van de patiënten met stadium III colonkanker (klierpositief) AC, terwijl het overlevingsvoordeel vergelijkbaar wordt verondersteld [32, 33]. Anderzijds zijn patiënten met SIBC in het algemeen ouder en hebben ze een slechtere nierfunctie ten gevolge van onder andere een slechte algehele gezondheid, roken en hydronefrose. Bovendien zal door het ontbreken van optimale middelen voor een adequate responspredictie op NAC of AC een substantieel deel van de patiënten overbehandeld worden (geschat $50 \%$ ) en derhalve blootgesteld worden aan significante toxiciteit $[7,9]$.
Studies over potentiële negatieve oncologische uitkomsten door uitstel van $\mathrm{RC}$ ten gevolge van de toepassing van NAC zijn niet voorhanden. Grossmann et al. [7] rapporteerden geen verschil in overleving voor patiënten met vitale tumorresten in het RC-preparaat tussen de NAC-groep en de controlegroep. In de interventie-, alsmede in de controlegroep, kwam $82 \%$ vs. $81 \%$ niet toe aan RC. Ondanks het reeds genoemde overlevingsvoordeel bij de toepassing van NAC bij cT2-4 N0- of Nx M0-BK-patiënten zijn er aanvullende studies nodig om de negatieve effecten van NAC bij patiënten die niet op de behandeling reageren, te onderzoeken, en om middelen te ontwikkelen waarmee een adequate respons of het uitblijven daarvan te voorspellen is. De huidige beperkingen kunnen in de toekomst wellicht weggenomen worden door de verdere moleculaire karakterisatie van $\mathrm{BK}$, innovatieve medische beeldvormingstechnieken en het onderzoeken van nieuwe en minder toxische systemische therapieën in een gerandomiseerde opzet [34, 35].

Belangrijke beperkingen van onze studie zijn het ontbreken van informatie over de typering van toegediende chemotherapeutica, het aantal toegediende cycli, alsmede het ontbreken van radiatiedoseringen en schema's. Tevens was een aanzienlijk deel van de patiënten gestadieerd als cTx, $\mathrm{cNx}$ of cMx. Wij erkennen verder dat de mate waarin PB wordt toegepast, mogelijk onderschat is in deze studie. Het aantal patiënten dat na NAR of NAC niet aan een RC toekwam door progressie van de ziekte of om andere redenen, is niet te achterhalen in de NKR. Evenmin was informatie over de algehele lichamelijke conditie en comorbiditeiten in de NKR voorhanden. Het effect van deze parameters op het ontvangen van NAC kon derhalve niet worden bepaald. Bovendien willen wij benadrukken dat de resultaten enkel de perioperatieve zorg in Nederland weerspiegelen. Het feit dat NAC (inclusief IC) in het NKI-AVL vaker wordt toegepast, zal mogelijk te maken hebben met een significant lagere leeftijd van de behandelpopulatie. Anderzijds zal de keuze voor het toepassen van NAC en strikte indicatiestelling ook een rol spelen, aangezien het type ziekenhuis ook een onafhankelijke voorspeller is in ons multivariate model. De data kunnen indicatief zijn voor de perioperatieve zorg in Europa, maar ze kunnen niet eenvoudigweg gegeneraliseerd worden.

Tot slot werden veranderingen in de TNM-classificatie die zich in de loop van de studieperiode voordeden ten aanzien van de positieve nodale stadiëring niet relevant geacht voor deze studie en op grond daarvan geaccepteerd. Deze veranderingen betroffen het ontbreken van het N3-stadium vóór 2002 en een wijziging in de definitie van dit stadium in 2010 van een lymfekliermetastase $>5 \mathrm{~cm}$ naar de aanwezigheid van lymfekliermetastasen ter hoogte van de aa. iliacae communes. 


\section{Conclusie}

Deze landelijke studie laat een belangrijke kentering zien in de perioperatieve behandelingen vanwege het spierinvasieve blaascarcinoom in de afgelopen twee decennia in $\mathrm{Ne}-$ derland. De stijging in de toepassing van neoadjuvante chemotherapie toont een langzame, maar gestage adaptatie van internationale richtlijnen in de huidige praktijk. Neoadjuvante chemotherapie wordt voornamelijk toegepast bij jongere patiënten, bij patiënten met extravesicale ziekte, in academische ziekenhuizen en in kankercentra. In tegenstelling tot neoadjuvante chemotherapie worden neoadjuvante radiotherapie, adjuvante radiotherapie en adjuvante chemotherapie nauwelijks (meer) toegepast.

Dankbetuiging Wij danken de registratiemedewerkers van het Integraal Kankercentrum Nederland (IKNL) voor de verzameling van data voor de Nederlandse Kanker Registratie en de wetenschappelijke staf van het Integraal Kankercentrum Nederland.

Open Access This article is distributed under the terms of the Creative Commons Attribution 4.0 International License (http:// creativecommons.org/licenses/by/4.0/), which permits unrestricted use, distribution, and reproduction in any medium, provided you give appropriate credit to the original author(s) and the source, provide a link to the Creative Commons license, and indicate if changes were made.

\section{Literatuur}

1. Zehnder P, Studer UE, Skinner EC, et al. Unaltered oncological outcomes of radical cystectomy with extended lymphadenectomy over three decades. BJU Int. 2013;112:51-8.

2. Huncharek M, Muscat J, Geschwind JF. Planned preoperative radiation therapy in muscle invasive bladder cancer; results of a metaanalysis. Anticancer Res. 1998;18:1931-4.

3. Leow JJ, Martin-Doyle W, Rajagopal PS, et al. Adjuvant chemotherapy for invasive bladder cancer: a 2013 updated systematic review and meta-analysis of randomized trials. Eur Urol. 2014;66:42-54.

4. Advanced Bladder Cancer Meta-analysis C. Neoadjuvant chemotherapy in invasive bladder cancer: update of a systematic review and meta-analysis of individual patient data advanced bladder cancer (ABC) meta-analysis collaboration. Eur Urol. 2005;48:202-5.

5. Zaghloul MS, Awwad HK, Akoush HH, Omar S, Soliman O, Attar I el. Postoperative radiotherapy of carcinoma in bilharzial bladder: improved disease free survival through improving local control. Int J Radiat Oncol Biol Phys. 1992;23:511-7.

6. Zargar H, Espiritu PN, Fairey AS, et al. Multicenter assessment of neoadjuvant chemotherapy for muscle-invasive bladder cancer. Eur Urol. 2015;67:241-9.

7. Grossman HB, Natale RB, Tangen CM, et al. Neoadjuvant chemotherapy plus cystectomy compared with cystectomy alone for locally advanced bladder cancer. N Engl J Med. 2003;349:859-66.

8. International Collaboration of T, Medical Research Council Advanced Bladder Cancer Working P, European Organisation for R, et al. International phase III trial assessing neoadjuvant cisplatin, methotrexate, and vinblastine chemotherapy for muscle-invasive bladder cancer: long-term results of the BA06 30894 trial. J Clin Oncol. 2011;29:2171-7.

9. Rosenblatt R, Sherif A, Rintala E, et al. Pathologic downstaging is a surrogate marker for efficacy and increased survival following neoadjuvant chemotherapy and radical cystectomy for muscle-invasive urothelial bladder cancer. Eur Urol. 2012;61:1229-38.

10. Reardon ZD, Patel SG, Zaid HB, et al. Trends in the use of perioperative chemotherapy for localized and locally advanced muscle-invasive bladder cancer: a sign of changing tides. Eur Urol. 2015;67:165-70.

11. Burger M, Mulders P, Witjes W. Use of neoadjuvant chemotherapy for muscle-invasive bladder cancer is low among major European centres: results of a feasibility questionnaire. Eur Urol. 2012;61:1070-1.

12. Thompson RH, Boorjian SA, Kim SP, et al. Eligibility for neoadjuvant/adjuvant cisplatin-based chemotherapy among radical cystectomy patients. BJU Int. 2014;113:17-21.

13. Canter D, Viterbo R, Kutikov A, et al. Baseline renal function status limits patient eligibility to receive perioperative chemotherapy for invasive bladder cancer and is minimally affected by radical cystectomy. Urology. 2011;77:160-5.

14. Donat SM, Shabsigh A, Savage C, et al. Potential impact of postoperative early complications on the timing of adjuvant chemotherapy in patients undergoing radical cystectomy: a high-volume tertiary cancer center experience. Eur Urol. 2009;55:177-85.

15. Hermans TJN, Fransen van de Putte EE, Simon Horenblas, Valery Lemmens, Katja Aben, Michiel S. van der Heijden, Laurens V. Beerepoot, Rob H. Verhoeven, Bas W.G. van Rhijn. Perioperative treatment and radical cystectomy for bladder cancer - a population based trend analysis of 10,338 patients in the Netherlands. Eur J Cancer. 2016;54:18-26.

16. Casparie M, Tiebosch AT, Burger G, et al. Pathology databanking and biobanking in The Netherlands, a central role for PALGA, the nationwide histopathology and cytopathology data network and archive. Cell Oncol. 2007;29:19-24.

17. Fritz APC, Jack A. International classicification of disease for oncology. Geneva: 3rd World Health Organization; 2000.

18. Sobin LH, Gospodarowicz GM, Wittekind C. TNM atlas, 7th. ed. Chichester, West Sussex, UK; Hoboken, NJ: Wiley-Blackwell; 2009.

19. Witjes JA, Compérat E, Cowan NC, et al. EAU guidelines on muscle-invasive and metastatic bladder cancer: summary of the 2013 guidelines. Eur Urol. 2014;65:778-92.

20. Mostofi FK, Sobin LH, Torloni H. Histological typing of urinary bladder tumours. International classification of tumours, no. 10. Genève: World Health Organization; 1973.

21. Rodel C, Grabenbauer GG, Kuhn R, et al. Combined-modality treatment and selective organ preservation in invasive bladder cancer: long-term results. J Clin Oncol. 2002;20:3061-71.

22. Oh KS, Soto DE, Smith DC, Montie JE, Lee CT, Sandler HM. Combined-modality therapy with gemcitabine and radiation therapy as a bladder preservation strategy: long-term results of a phase I trial. Int J Radiat Oncol Biol Phys. 2009;74:511-7.

23. Zaghloul MS. The need to revisit adjuvant and neoadjuvant radiotherapy in bladder cancer. Expert Rev Anticancer Ther. 2010;10:1527-8.

24. Granfors T, Tomic R, Ljungberg B. Downstaging and survival benefits of neoadjuvant radiotherapy before cystectomy for patients with invasive bladder carcinoma. Scand J Urol Nephrol. 2009;43:293-9.

25. Sternberg CN, Skoneczna I, Kerst JM, et al. Immediate versus deferred chemotherapy after radical cystectomy in patients with pT3pT4 or N+ M0 urothelial carcinoma of the bladder (EORTC 30994): an intergroup, open-label, randomised phase 3 trial. Lancet Oncol. 2015;16:76-86.

26. Mertens LS, Meijer RP, Meinhardt W, et al. Occult lymph node metastases in patients with carcinoma invading bladder muscle: incidence after neoadjuvant chemotherapy and cystectomy vs after cystectomy alone. BJU Int. 2014;114:67-74.

27. Zargar-Shoshtari K, Zargar H, Lotan Y, et al. A multi-institutional anlaysis of outcomes in patients with clinically node positive 
urothelial bladder cancer treated with induction chemotherapy and radical cystectomy. J Urol. 2016;195(1):53-9.

28. Goossen-Laan CA, Leliveld AM, Verhoeven RH, et al. Effects of age and comorbidity on treatment and survival of patients with muscle-invasive bladder cancer. Int J Cancer. 2014;135(4):905-12.

29. Bamias A, Efstathiou E, Moulopoulos LA, et al. The outcome of elderly patients with advanced urothelial carcinoma after platinumbased combination chemotherapy. Ann Oncol. 2005;16:307-13.

30. Goossens-Laan CA, Visser O, Wouters MW, et al. Variations in treatment policies and outcome for bladder cancer in the Netherlands. Eur J Surg Oncol. 2010;36(Suppl):100-7.

31. Moertel CG, Fleming TR, Macdonald JS, et al. Intergroup study of fluorouracil plus levamisole as adjuvant therapy for stage II/Dukes' B2 colon cancer. J Clin Oncol. 1995;13:2936-43.

32. Broek CB van den, Bastiaannet E, Dekker JW, et al. Time trends in chemotherapy (administration and costs) and relative survival in stage III colon cancer patients - a large population-based study from 1990 to 2008. Acta Oncol. 2013;52:941-9.

33. Chakiba C, Cornelis F, Descat E, et al. Dynamic contrast enhanced MRI-derived parameters are potential biomarkers of therapeutic response in bladder carcinoma. Eur J Radiol. 2015;84:1023-8.
34. Powles T, Eder JP, Fine GD, et al. MPDL3280A (anti-PD-L1) treatment leads to clinical activity in metastatic bladder cancer. Nature. 2014;515:558-62.

35. Groenendijk FH, Jong $\mathbf{J}$ de, Fransen PEE van de, et al. ERBB2 Mutations Characterize a Subgroup of Muscle-invasive Bladder Cancers with Excellent Response to Neoadjuvant Chemotherapy. Eur Urol. 2016;69(3):384-8.

drs. Tom J.N. Hermans aios urologie

drs. Elisabeth E. Fransen van de Putte arts-onderzoeker urologie

prof. dr. Simon Horenblas uroloog

dr. Valery Lemmens epidemioloog

dr. Katja Aben epidemioloog

dr. Michiel S. van der Heijden oncoloog

dr. Laurens V. Beerepoot oncoloog

dr. Rob H. Verhoeven epidemioloog

dr. Bas W.G. van Rhijn uroloog 